\title{
PENERAPAN METODE PROFILE MATCHING DAN LINEAR CONGRUENT METHOD UNTUK MENENTUKAN SOAL PENENTUAN KONSENTRASI MATA KULIAH
}

\author{
${ }^{1}$ M Khoirul Hakim AR, ${ }^{2}$ Usep Saprudin, ${ }^{3} \mathrm{M}$ Reza Redo Islami \\ Program Studi Teknik Informatika, STMIK Dharma Wacana \\ 1․mkhoirulhakimar21@gmail.com, ${ }^{2}$ usepkreatif@gmail.com, ${ }^{3}$ reza.redo@hotmail.com
}

Jalan Kenanga No.3, Mulyojati 16c Kota Metro

\begin{abstract}
ABSTRAK
Sekolah Tinggi Ilmu Manajemen Informatika dan Komputer (STMIK) merupakan perguruan tinggi swasta di Kota Metro, yang berfokus pada pendidikan guna pengembangan sumber daya manusia di bidang komputer. Mahasiswa STMIK Dharma Wacana tidak hanya berasal dari dalam daerah Kota Metro saja bahkan ada juga yang berasal dari luar daerah Kota Metro. Jumlah mahasiswa yang semakin meningkat mendorong STMIK Dharma Wacana untuk terus meningkatkan kualitas layanan baik dalam bidang akademik maupun nonakademik. Salah satu wujud layanan STMIK Dharma Wacana di bidang Akademik adalah dosen yang membimbing mahasiswa mulai dari semester awal hingga semester akhir. Pada proses pengambilan mata kuliah konsentrasi, mahasiswa menghadap ke dosen pembimbing akademik, pada proses tersebut dosen akan melihat nilai mahasiswa sehingga dengan nilai tersebut dosen akan melakukan tanya jawab dan memberikan soal seputaran konsentrasi mata kuliah, soal yang diberikan sering mengalami kesamaan antara mahasiswa satu dengan mahasiswa lainnya. Secara prosedur yang benar, proses pengambilan mata kuliah konsentrasi dilakukan dengan cara penawaran dan dilakukannya tes dengan soal-soal yang mengarah ke konsentrasi bidang mata kuliah, namun faktanya mahasiswa masih mengikuti saran yang diberikan oleh dosen pembimbing akademik. Hal ini membuat mahasiswa tidak dapat memilih mata kuliah konsentrasi yang susuai dengan keinginan dan kemampuan yang dimiliki. proses pengambilan mata kuliah konsentrasi, Mengetahui kemampuan konsentrasi sangatlah penting bagi dosen dan mahasiswa untuk menentukan mata kuliah konsentrasi yang akan diambil sesuai dengan potensi pada mahasiswa. Mengetahui kemampuan mahasiswa sebaiknya menggunakan metode Profile Matching yang mampu memberikan rekomendasi dengan nilai terdekat sesuai dengan kemampuan seseorang serta menggunakan metode Linear congruent method (LCM) yang dapat digunakan untuk pengacakan soal-soal yang bertujuan agar setiap orang akan mendapatkan soal yang berbeda.
\end{abstract}

Kata kunci : Menentukan, soal, Konsentrasi, matakuliah.

\section{PENDAHULUAN}

Sekolah Tinggi Ilmu Manajemen Informatika dan Komputer (STMIK) merupakan perguruan tinggi swasta di Kota Metro, yang berfokus pada pendidikan guna pengembangan sumber daya manusia di bidang komputer. Mahasiswa STMIK Dharma Wacana tidak hanya berasal dari dalam daerah Kota Metro saja bahkan ada juga yang berasal dari luar daerah Kota Metro. Jumlah mahasiswa yang semakin meningkat mendorong STMIK Dharma Wacana untuk terus meningkatkan kualitas layanan baik dalam bidang akademik maupun nonakademik.
Salah satu wujud layanan STMIK Dharma Wacana di bidang Akademik adalah dosen yang membimbing mahasiswa mulai dari semester awal hingga semester akhir. Pada proses pengambilan mata kuliah konsentrasi, Mahasiswa menghadap ke dosen pembimbing akademik, pada proses tersebut dosen akan melihat nilai mahasiswa sehingga dengan nilai tersebut dosen akan melakukan tanya jawab kepada mahasiswa untuk menentukan konsentrasi yang akan diambil. Secara prosedur yang benar, proses pengambilan mata kuliah konsentrasi dilakukan dengan cara penawaran dan dilakukannya tes dengan soal-soal yang mengarah ke konsentrasi bidang mata kuliah, namun faktanya mahasiswa masih mengikuti saran yang diberikan oleh dosen 
pembimbing akademik. Hal ini membuat mahasiswa tidak dapat memilih mata kuliah konsentrasi yang susuai dengan keinginan dan kemampuan yang dimiliki.

Pada proses pengambilan mata kuliah konsentrasi, Mengetahui kemampuan konsentrasi sangatlah penting bagi dosen dan mahasiswa untuk menentukan mata kuliah konsentrasi yang akan diambil sesuai dengan kemampuan pada mahasiswa. Pada penelitian sebelumnya yang kerap digunakan yaitu metode profile matching, metode profile matching dipilih karena metode ini mampu memberikan rekomendasi dengan nilai terdekat sesuai dengan kemampuan seseorang. Sedangkan di penelitian lainnya sebagai pengacakan soal menggunakan metode Linear congruent method (LCM) metode ini digunakan untuk pengacakan soal-soal yang bertujuan agar setiap orang akan mendapatkan soal yang berbeda. Dari kedua penjabaran method tersebut memungkinkan untuk diterapkan secara bersamaan kedalam sebuah proses mengetahui soal yang sesuai dengan konsentrasi bidang pada setiap seseorang.

\subsection{Tujuan Penelitian}

Menerapkan metode profile matching dan Linear congruent method (LCM) untuk menentukan soal penentuan konsentrasi mata kuliah.

\section{METODE PENELITIAN}

Metode yang akan digunakan dalam penelitian ini meliputi dua bagian yaitu metode pengumpulan data dan metode pemecahan masalah.

\subsection{Metode Pengumpulan Data}

a) Observasi

Dengan cara ini peneliti melakukan pengamatan langsung kepada dosen dan mahasiswa STMIK
Dharma Wacana Metro yang telah mengambil mata kuliah konsentrasi.

b) Wawancara

Dengan teknik ini peneliti melakukan wawancara langsung kepada dosen dan mahasiswa yang telah mengambil mata kuliah konsentrasi, berupa sebaran kuisioner kepada mahasiswa agar nantinya data tersebut menjadi acuan.

c) Studi Pustaka

Pada metode ini peneliti mengumpulkan data-data dari buku, artikel ilmiah, jurnal ilmiah dan internet yang dibahas pada penelitian ini.

\subsection{Metode Pemecahan Masalah}

Dalam penelitian ini menggunakan metode Profile Matching sebagai pencocokan profil nantinya akan digunakan sebagai cara untuk menentukan jenis tipe soal yang akan keluar berdasarkan profil mahasiswa yang diambil dari daftar nilai sementara (DNS) setelah tipe soal telah ditentukan selanjutnya akan di acak menggunakan metode linear congruent method untuk mendapatkan hasil output simulasi soal tiap mahasiswa terhadap mata kuliah pendukung konsentrasi kejuruan yaitu pada jurusan Teknik Informatika (TI) terdapat Mobile Computing (MC) dan Artificial Intelligence (AI), dan pada jurusan Teknik Informasi (SI) terdapat Application Development (AD) dan Enterprise Resource Planning (ERP).

Hasil dari penerapan metode Profile Matching tersebut nantinya akan menjadi dasar bagaimana soal-soal akan dikeluarkan berdasarkan mata kuliah pendukung konsentrasi kejuruan pada jurusan Teknik Informatika dan Sistem Informasi dan selanjutnya akan diterapkan kedalam metode Linear Congruent Method (LCM) yang digunakan untuk 
pengacakan soal-soal bertujuan agar setiap mahasiswa mendapatkan soal yang berbeda. telah dibuat klasifikasi daftar mata kuliah yang saling terhubung dengan konsentrasi kejuruan masingmasing. Hasil klasifkasinya sebagai berikut:

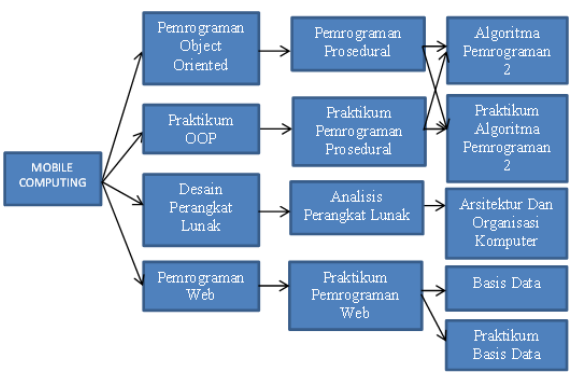

Gambar 2.1 Mata Kuliah Konsentrasi Mobile Computing.

Tabel 2.2 Mata Kuliah Konsentrasi Artificial Intelligence (AI).

\begin{tabular}{|c|c|c|c|}
\hline $\begin{array}{c}\text { Semes } \\
\text { ter }\end{array}$ & Mata Kuliah & Persyaratan & Kode \\
\hline 1 & Kalkulus 1 & & MKK \\
\hline 1 & Aljabar Linier & & MKK \\
\hline 2 & Kalkulus 2 & Kalkulus 1 & MKK \\
\hline 2 & Logika Matematika & & MKK \\
\hline 3 & Analisis Perangkat Lunak & & MKK \\
\hline 3 & Metode Numerik & & MKK \\
\hline 4 & Desain Perangkat Lunak & $\begin{array}{c}\text { Analisis } \\
\text { Perangkat Lunak }\end{array}$ & MKB \\
\hline 4 & Statistik dan Probabilitas & & MKK \\
\hline
\end{tabular}

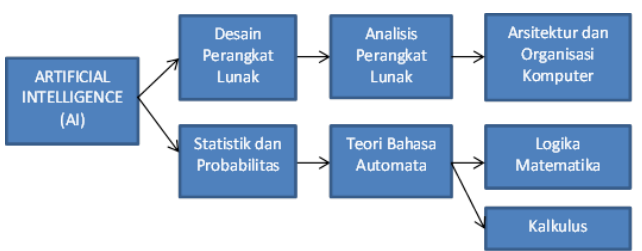

Gambar 2.2 Mata Kuliah Konsentrasi Artificial Intelligence (AI).

Tabel 2.3 Mata Kuliah Konsentrasi Application Development (AD).

\begin{tabular}{|c|c|c|c|}
\hline $\begin{array}{c}\text { Semes } \\
\text { ter }\end{array}$ & Mata Kuliah & Persyaratan & Kode \\
\hline 1 & Algoritma dan Pemrograman & & MKK \\
\hline 1 & Konsep Sistem Informasi & & MKK \\
\hline 1 & $\begin{array}{c}\text { Praktek Algoritma dan } \\
\text { Pemrograman }\end{array}$ & & MKK \\
\hline 2 & Basis Data & & MKK \\
\hline 2 & Jaringan Komputer & & MKK \\
\hline 2 & Sistem Operasi & $\begin{array}{c}\text { Konsep Sistem } \\
\text { Informasi }\end{array}$ & MKK \\
\hline 3 & Pemrograman Web & & MKB \\
\hline 4 & Pemrograman Web Dinamis & $\begin{array}{c}\text { Pemrograman } \\
\text { Web }\end{array}$ & MKB \\
\hline
\end{tabular}

\begin{tabular}{|c|c|c|c|}
\hline $\begin{array}{c}\text { Sem } \\
\text { ester }\end{array}$ & Mata Kuliah & Persyaratan & Kode \\
\hline 1 & Algoritma Pemrograman 1 & MKK \\
\hline 1 & $\begin{array}{c}\text { Praktikum Algoritma } \\
\text { Pemrograman 1 }\end{array}$ & MKK \\
\hline 1 & Struktur Data & MKK \\
\hline 2 & Algoritma Pemrograman 2 & $\begin{array}{c}\text { Algoritma } \\
\text { Pemrograman 1 }\end{array}$ & MKK \\
\hline 2 & $\begin{array}{c}\text { Praktikum Algoritma } \\
\text { Pemrograman 2 } \\
\text { Pemrograman 1 }\end{array}$ & MKK \\
\hline 2 & Basis Data & Struktur Data & MKK \\
\hline 2 & Praktikum Basis Data & MKK \\
\hline 3 & Pemrograman Web & MKK \\
\hline 3 & Pemrograman Prosedural & MKK \\
\hline 3 & $\begin{array}{c}\text { Praktikum Pemrograman } \\
\text { Prosedural }\end{array}$ & MKK \\
\hline 3 & Analisis Perangkat Lunak & MKK \\
\hline 3 & $\begin{array}{c}\text { Praktikum Pemrograman } \\
\text { Web }\end{array}$ & $\begin{array}{c}\text { Pemrograman } \\
\text { Prosedural }\end{array}$ & MKB \\
\hline 4 & $\begin{array}{c}\text { Pemrograman Object } \\
\text { Oriented }\end{array}$ & Progedural \\
\hline 4 & Praktikum OOP & MKB \\
\hline 4 & Desain Perangkat Lunak & MKB \\
\hline
\end{tabular}

\begin{tabular}{l|l}
$\begin{array}{c}\text { APPLICATION } \\
\text { DEVEEOPMENT } \\
\text { (AD) }\end{array}$ & $\rightarrow \begin{array}{l}\text { Pemrograman } \\
\text { Web Dinamis }\end{array}$ \\
\hline
\end{tabular}

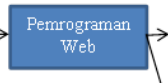

Sistem Basis Data

Struktur Data

Gambar 2.3 Mata Kuliah Konsentrasi Application Development (AD).

ERP

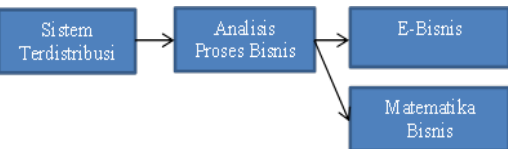

Gambar 2.4 Mata Kuliah Konsentrasi Enterprise Resource Planning (ERP).

Tabel 2.4 Mata Kuliah Konsentrasi Enterprise Resource Planning (ERP).

\begin{tabular}{|c|c|c|c|}
\hline $\begin{array}{c}\text { Seme } \\
\text { ster }\end{array}$ & Mata Kuliah & Persyaratan & Kode \\
\hline 1 & Akuntansi & & MKK \\
\hline 2 & Basis Data & & MKK \\
\hline 2 & Jaringan Komputer & & MKK \\
\hline 2 & $\begin{array}{c}\text { Perancangan Sistem } \\
\text { Informasi }\end{array}$ & & MKB \\
\hline 3 & Analisis Proses Bisnis & Analisis \\
\hline 4 & Sistem Terdistribusi & Proses Bisnis & MKK \\
\hline
\end{tabular}

\subsection{Metode Profile Matching}

Profile Matching adalah sebuah mekanisme pengambilan keputusan dengan mengasumsikan bahwa terdapat tingkat variabel prediktor yang ideal yang dimiliki oleh mahasiswa, bukannya tingkat minimal yang harus dipenuhi atau dilewati.

Dalam pencocokan profil, dilakukan identifikasi terhadap daftar nilai sementara (DNS) mahasiswa. 
Setelah proses profile matching selesai, nilai-nilai yang keluar akan dijadikan untuk penentuan soal yang akan dibuat. Soal yang akan dibuat terdapat 3 kriteria yaitu mudah, sedang dan sulit. dalam kelompok tersebut diukur menggunakan penilaian terhadap daftar nilai sementara (DNS). Tahapan dalam metode profile matching adalah sebagai berikut :

1) Menentukan Bobot Nilai Gap. Pada tahap ini, akan ditentukan bobot nilai masing-masing aspek dengan menggunakan bobot nilai yang telah ditentukan bagi masing-masing aspek itu sendiri. Adapun inputan dari proses pembobotan ini adalah nilai DNS mahasiswa.

2) Langkah kedua dengan melakukan pemetaan Gap. Gap yang dimaksud adalah selisih nilai DNS mahasiswa.

3) Melakukan pencocokan dengan tabel bobot Gap dan Hasil Gap dari pengurangan DNS mahasiswa bila dicocokkan dengan kolom selisih gap pada table bobot nilai yang dihasilkan sama.

4) Melakukan perhitungan core factor dan secondary factor. Setelah menentukan bobot nilai Gap untuk beberapa aspek yang dibutuhkan, kemudian tiap aspek dikelompokkan lagi menjadi dua kelompok yaitu core factor dan secondary factor. menggunakan rumus dibawah ini:

\section{$\frac{\mathrm{NCF}=\mathrm{NC}(\mathrm{P} 1, \mathrm{P} 2)}{\mathrm{IC}}$}

Keterangan :

$\mathrm{NCF}(\mathrm{P} 1) \quad$ : Nilai rata-rata core factor

$\mathrm{NC}(\mathrm{P} 1, \mathrm{P} 2) \quad$ : Jumlah total nilai core factor (P1,P2)

IC : Jumlah item core factor

$$
\frac{\mathrm{NSF}=\mathrm{NS}(\mathrm{P} 1, \mathrm{P} 3)}{\mathrm{IS}}
$$

Keterangan

$\mathrm{NSF}(\mathrm{P} 1)$ : Nilai rata-rata secondary factor

NS(P1,P3): Jumlah total nilai secondary factor (P1,P3)

IS : Jumlah item secondary factor
5) Perhitungan Penentuan Rangking dengan rumus sebagai berikut:

Ranking $=(\mathrm{x}) \% \mathrm{NCF}(\mathrm{P} 1, \mathrm{P} 2)+(\mathrm{x}) \% \mathrm{NSF}(\mathrm{P} 1, \mathrm{P} 3)=$ $\mathrm{N}(\mathrm{P} 1, \mathrm{P} 2, \mathrm{P} 3)$

$\mathrm{NCF}(\mathrm{P} 1, \mathrm{P} 2)$ : Nilai rata-rata core factor $(\mathrm{P} 1, \mathrm{P} 2)$

$\mathrm{NSF}(\mathrm{P} 1, \mathrm{P} 3)$ : Nilai rata-rata secondary factor $(\mathrm{P} 1, \mathrm{P} 3)$

$\mathrm{N}(\mathrm{P} 1, \mathrm{P} 2, \mathrm{P} 3)$ : Nilai total dari aspek (P1,P2,P3)

(x)\%: Nilai persen yang diinputkan

\subsection{Metode Linear Congruent Method (LCM)}

Linear Congruent Method (LCM) memanfaatkan model linier untuk membangkitkan bilangan acak. Metode ini akan digunakan untuk pengacakan soal berdasarkan tipe soal yang sudah dilakukan dengan metode profile matching bertujuan agar tidak terjadi pengulangan pada soal berikutnya. yang didefinisikan dengan rumus sebagai berikut:

$$
\mathrm{xn}+1=(\mathrm{a} \mathrm{xn}+\mathrm{c})(\bmod \mathrm{m})
$$

Keterangan :

$\mathrm{a} \quad=$ Urutan peserta

c = Jumlah soal tiap peserta (soal mudah/ sedang/ sulit)

$\mathrm{xn} \quad=$ Urutan soal

$\mathrm{m}$ = Jumlah soal yang tersedia (soal mudah/ sedang/ sulit)

dimana xn adalah bil. acak ke n,a dan c adalah konstanta LCM

$\mathrm{m}$ adalah batas maksimum bilangan acak.

contoh seperti di bawah ini :

Rumus :

$$
\mathrm{xn}+1=(\mathrm{a} \mathrm{xn}+\mathrm{c})(\bmod \mathrm{m})
$$

diketahui:

$\mathrm{a} \quad=2($ Urutan peserta)

c $=6$ (Jumah soal tiap peserta (soal mudah/ sedang/ sulit))

xo $=0$ (Urutan soal)

$\mathrm{m}=101 \quad$ (Jumlah soal yang tersedia (soal mudah/sedang/ sulit))

Penyelesaian : 


\begin{tabular}{|c|c|c|c|}
\hline $\begin{array}{c}\text { HASIL PERHITUNGAN } \\
\text { MANUAL }\end{array}$ & \multicolumn{3}{|c|}{$\begin{array}{l}\text { HASIL PERHITUNGAN } \\
\text { EXEL }\end{array}$} \\
\hline $\begin{array}{l}X(0)=0 \\
X(1)=(2(1)+6) \bmod 101=\mathbf{8} \\
X(2)=(2(8)+6) \bmod 101=\mathbf{2 2} \\
X(3)=(2(22)+6) \bmod 101=\mathbf{5 0} \\
X(4)=(2(50)+6) \bmod 101=\mathbf{5} \\
X(5)=(2(5)+6) \bmod 101=\mathbf{1 6} \\
X(6)=(2(16)+6) \bmod 101=\mathbf{3 8}\end{array}$ & $\begin{array}{l}5 \\
6\end{array}$ & $\begin{array}{c}a \\
X_{n}+c \\
8 \\
8\end{array}$ & $\begin{array}{l}50 \\
5 \\
16 \\
38\end{array}$ \\
\hline
\end{tabular}

\section{HASIL DAN PEMBAHASAN}

\subsection{Penerapan Metode Profile Matching}

Sebelum masuk ke tahapan metode profile matching, penulis membuat klasifikasi mengenai daftar mata kuliah yang akan diterapkan ke dalam metode profile matching. Mata kuliah pada setiap jurusan ada beberapa kriteria yaitu mata kuliah inti (P1), mata kuliah pendukung 1 (P2), dan mata kuliah pendukung 2 (P3). Dari hasil penerapan metode profie matching nantinya akan dijadikan penentuan kategori soal (mudah, sedang dan sulit) sebagai acuan untuk melakukan proses pengacakan soal-soal yang dilakukan menggunakan metode linear congruent method. Nilai yang diinputkan dirubah menjadi angka yaitu $A=4, B=3, C=2, D=1$. Jika terdapat mahasiswa yang mendapatkan nilai 0 maka tidak dapat diinptkan kedalam tabel pemetaan Gap, begitu pula mata kuliah yang terhubung dengan mata kuliah tersebut tidak dapat dihitung kedalam pemetaan Gap. Nilai yang akan diinputkan tidak semua merupakan data real, hal ini dikarenakan data DNS yang diambil merupakan hasil data dari kurikulum yang lama, sedangkan pada penelitian ini perhitungan profie matching berdasarkan kurikulum baru. Pemetaan Gap yang dilakukan terdapat dua tahap dengan menghitung selisih P1 terhadap P2 dan P1 terhadap P3.

Dan berikut hasil klasifikasi daftar mata kuliah.

a) Daftar Mata Kuliah Jurusan Teknik Informatika (TI).
Terdapat daftar mata kuliah pada jurusan Teknik Informatika yang saling terhubung antara mata kuliah inti (P1) dengan mata kuliah pendukung (P2,P3) dan diberi nama dengan variabel $\mathrm{H} 1, \mathrm{H} 2$, H3, H4, H5 dan seterusnya. Yang telah di klasifikasi pada Tabel 4.1 berikut.

Tabel 3.1 Daftar Mata Kuliah Inti (P1) Dan Pendukung (P2,P3) Teknik Informatika (TI).

\begin{tabular}{|c|c|c|c|}
\hline \multicolumn{4}{|c|}{$\begin{array}{l}\text { MATA KULIAH INTI (P1) DAN PENDUKUNG (P2,P3) TEKNIK } \\
\text { INFORMATIKA (TI) }\end{array}$} \\
\hline VARIABEL & P1 & P2 & P3 \\
\hline \multirow[b]{2}{*}{$\mathrm{H} 1$} & \multirow{2}{*}{$\begin{array}{c}\text { Pemrograman } \\
\text { Object } \\
\text { Oriented }\end{array}$} & \multirow{2}{*}{$\begin{array}{l}\text { Pemrograman } \\
\text { Prosedural }\end{array}$} & $\begin{array}{c}\text { Algoritma } \\
\text { Pemrograman } \\
2\end{array}$ \\
\hline & & & $\begin{array}{c}\text { Praktikum } \\
\text { Algoritma } \\
\text { Pemrograman } \\
2\end{array}$ \\
\hline \multirow[b]{2}{*}{$\mathrm{H} 2$} & \multirow{2}{*}{$\begin{array}{l}\text { Praktikum } \\
\text { OOP }\end{array}$} & \multirow{2}{*}{$\begin{array}{l}\text { Praktikum } \\
\text { Pemrograman } \\
\text { Prosedural }\end{array}$} & $\begin{array}{c}\text { Algoritma } \\
\text { Pemrograman } \\
2 \\
\end{array}$ \\
\hline & & & $\begin{array}{c}\text { Praktikum } \\
\text { Algoritma } \\
\text { Pemrograman } \\
2\end{array}$ \\
\hline $\mathrm{H} 3$ & $\begin{array}{c}\text { Desain } \\
\text { Perangkat } \\
\text { Lunak }\end{array}$ & $\begin{array}{c}\text { Analisis } \\
\text { Perangkat } \\
\text { Lunak } \\
\end{array}$ & $\begin{array}{c}\text { Arsitektur dan } \\
\text { Organisasi } \\
\text { Komputer } \\
\end{array}$ \\
\hline \multirow{2}{*}{$\mathrm{H} 4$} & \multirow{2}{*}{$\begin{array}{l}\text { Pemrograman } \\
\text { Web Dinamis }\end{array}$} & \multirow{2}{*}{$\begin{array}{l}\text { Praktikum } \\
\text { Pemrograman } \\
\text { Web }\end{array}$} & Basis Data \\
\hline & & & $\begin{array}{l}\text { Praktikum } \\
\text { Basis Data }\end{array}$ \\
\hline \multirow{2}{*}{ H5 } & \multirow{2}{*}{$\begin{array}{l}\text { Statistik dan } \\
\text { Probabilitas }\end{array}$} & \multirow{2}{*}{$\begin{array}{l}\text { Teori Bahasa } \\
\text { Automata }\end{array}$} & Kalkulus \\
\hline & & & $\begin{array}{c}\text { Logika } \\
\text { Matematika }\end{array}$ \\
\hline
\end{tabular}

b) Daftar Mata Kuliah Jurusan Sistem Informatika (SI).

Pada Tabel 4.6 terdapat daftar mata kuliah pada jurusan Sistem Informasi yang saling terhubung antara mata kuliah inti (P1) dan mata kuliah pendukung (P2,P3).

Tabel 3.2 Daftar Mata Kuliah Inti (P1) Dan Pendukung (P2,P3) Sistem Informasi (SI).

\begin{tabular}{|c|c|c|c|}
\hline \multicolumn{5}{|c|}{ MATA KULIAH INTI (P1) DAN PENDUKUNG (P2,P3) } \\
SISTEM INFORMASI (SI) \\
\hline VARIABEL & P1 & P2 & P3 \\
\hline \multirow{2}{*}{ H1 } & $\begin{array}{c}\text { Pemrograman } \\
\text { Web Dinamis }\end{array}$ & $\begin{array}{c}\text { Pemrograman } \\
\text { Web }\end{array}$ & $\begin{array}{c}\text { Sistem } \\
\text { Basis Data }\end{array}$ \\
\cline { 4 - 4 } & H2 & $\begin{array}{c}\text { Struktur } \\
\text { Data }\end{array}$ \\
\hline \multirow{2}{*}{ Sistem } & $\begin{array}{c}\text { Analisis } \\
\text { Proses Bisnis }\end{array}$ & \begin{tabular}{c} 
E-Bisnis \\
\cline { 4 - 4 }
\end{tabular} & $\begin{array}{c}\text { Matematika } \\
\text { Bisnis }\end{array}$ \\
\hline
\end{tabular}

Selanjutnya perhitungan yang dilakukan mengikuti tahapan metode Profile Matching.

Dan berikut hasil ahkir dari metode Profile Matching. 
Tabel 3.3 Hasil Akhir Proses Profile Matching Mata Kuliah Konsentrasi Application Development (SI).

\begin{tabular}{|c|c|c|c|c|}
\hline \multicolumn{5}{|c|}{$\begin{array}{l}\text { HASIL AKHIR MATA KULIAH KONSENTRASI APLICATION } \\
\text { DEVELOPMENT (SI) }\end{array}$} \\
\hline No & \multicolumn{2}{|c|}{ NAMA MHS } & \multirow{2}{*}{$\begin{array}{c}\begin{array}{c}\text { NILAI CF } \\
\& \mathrm{SF}\end{array} \\
4,5\end{array}$} & \multirow{2}{*}{$\begin{array}{c}\begin{array}{c}\text { HASII } \\
\text { AKHI } \\
\mathbf{R}\end{array} \\
\end{array}$} \\
\hline \multirow{2}{*}{1} & \multirow{2}{*}{ SITI KHOIRIAH } & CF P1-P2 & & \\
\hline & & SF P1-P3 & 4,75 & 4,6 \\
\hline \multirow{2}{*}{2} & \multirow{2}{*}{ M LUTHFI HAFIDZ } & CF P1-P2 & 4,5 & \multirow{2}{*}{4,5} \\
\hline & & SF P1-P3 & 4,5 & \\
\hline \multirow{2}{*}{3} & \multirow{2}{*}{ IMAM SUBAKTI } & CF P1-P2 & 5 & \multirow{2}{*}{4,9} \\
\hline & & SF P1-P3 & 4,75 & \\
\hline \multirow{2}{*}{4} & \multirow{2}{*}{ NURUL ERIYANI } & CF P1-P2 & 4,5 & \multirow{2}{*}{4,5} \\
\hline & & SF P1-P3 & 4,5 & \\
\hline \multirow{2}{*}{5} & \multirow{2}{*}{$\begin{array}{l}\text { M GHIFARY } \\
\text { IQBAL }\end{array}$} & CF P1-P2 & 5 & \multirow{2}{*}{4,8} \\
\hline & & SF P1-P3 & 4,5 & \\
\hline \multirow{2}{*}{6} & \multirow{2}{*}{ OKKE STEVANUS } & CF P1-P2 & 5 & \multirow{2}{*}{4,9} \\
\hline & & SF P1-P3 & 4,75 & \\
\hline \multirow{2}{*}{7} & \multirow{2}{*}{ RISWAN HASBID } & CF P1-P2 & 4 & \multirow{2}{*}{4,2} \\
\hline & & SF P1-P3 & 4,5 & \\
\hline \multirow{2}{*}{8} & \multirow{2}{*}{$\begin{array}{c}\text { KOMANG } \\
\text { YUDHISTIRA }\end{array}$} & CF P1-P2 & 5 & \multirow{2}{*}{4,9} \\
\hline & & SF P1-P3 & 4,75 & \\
\hline \multirow{2}{*}{9} & \multirow{2}{*}{ SITI ROMLAH } & CF P1-P2 & 4,5 & \multirow{2}{*}{4,6} \\
\hline & & SF P1-P3 & 4,75 & \\
\hline \multirow{2}{*}{10} & \multirow{2}{*}{ YUDI PRASETYO } & CF P1-P2 & - & \multirow{2}{*}{ - } \\
\hline & & SF P1-P3 & - & \\
\hline
\end{tabular}

Tabel 3.4 Hasil Akhir Proses Profile Matching Mata Kuliah Konsentrasi ERP (SI).

\begin{tabular}{|c|c|c|c|c|}
\hline \multicolumn{3}{|c|}{ HASIL AKHIR MATA KULIAH KONSENTRASI ERP (SI) } \\
\hline \multirow{2}{*}{ NO } & \multicolumn{2}{|c|}{ NAMA MHS } & $\begin{array}{c}\text { NILAI } \\
\text { CF \& SF }\end{array}$ & HASIL \\
AKHIR
\end{tabular}

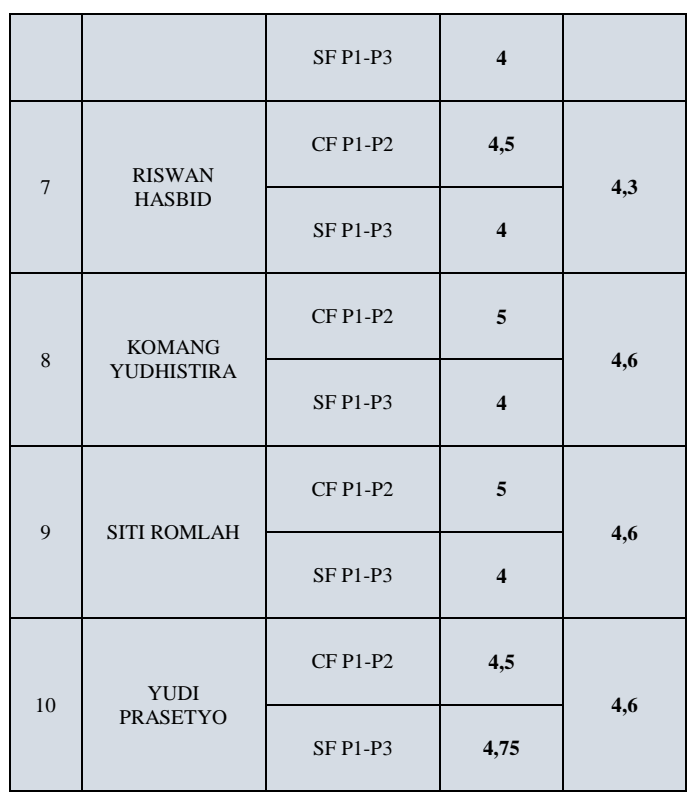

Setelah setiap mahasiswa mendapatkan hasil akhir berdasarkan konsentrasi dan jurusannya masingmasing seperti tabel diatas, maka bisa ditentukan peringkat atau ranking dari penilaian mata kuliah konsentrasi, semakin besarnya nilai hasil akhir maka semakin besar pula kesempatan untuk mengambil mata kuliah konsentrasi sesuai dengan jurusan yang diambil, begitu pula sebaliknya.

\subsection{Penerapan Metode Linear Congruent Method}

Pada tahap penerapan metode Linear congruent method sebelum melanjutkan ke tahapan pengacakan soal-soal diperlukan penentuan kategori soal sebagai dasarnya. Menentukan kategori soal dilihat dari hasil penilaian yang telah dihitung menggunakan metode profie matching. Dari hasil perhitungan profile matching akan dikelompokkan menjadi tiga kategori soal yaitu mudah, sedang dan sulit berdasarkan konsentrasi kejuruan masing-masing. Dari hasil pengelompokan tersebut akan dilakukan proses pengacakan soal yang diharapkan tidak terjadinya pengulangan pada soal selanjutnya. Adapun proses penerapan metode Linear congruent method terlihat pada Gambar berikut: 


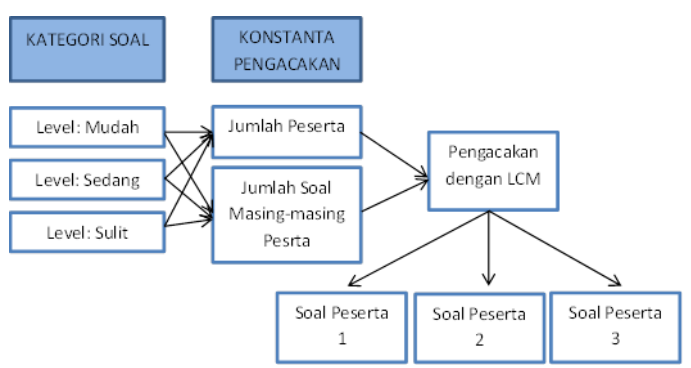

Gambar 3.1 Proses Penerapan Linear Congruent Method dalam pengacakan soal.

a) Penentuan Kategori Soal

Dalam penentuan kategori soal diharapkan setiap soal memiliki bobot yang sama. Dengan penentuan kategori soal ini maka setiap mahasiswa akan mendapatkan proporsi soal yang berbeda-beda sesuai dengan kemampuan dan hasil perhitungan yang telah dilakukan menggunakan metode profile matching. Menurut (Arikunto, 2006:210), menentukan layaknya soal perlu memperhatikan tujuan penggunaan soal, jika soal tes digunakan untuk memperoleh pencapaian hasil belajar siswa/siswi, maka soal tes cenderung menggunakan soal yang tidak terlalu mudah dan tidak terlalu sulit. Oleh karena itu, bisa dikatakan bahwa untuk Ujian Tengah Semester yang bertujuan untuk mengukur pencapaian hasil belajar siswa, soal tes yang digunakan adalah soal yang tidak terlalu sulit dan tidak terlalu mudah.

Soal yang baik yaitu soal yang tidak terlalu mudah atau tidak terlalu sulit. Hal ini sejalan dengan pendapat (Arifin, 2009:270) yang menyatakan bahwa, untuk memperoleh prestasi belajar yang baik, sebaiknya proporsi antara tingkat kesulitan soal tersebar secara normal. Perhitungan proporsi tersebut dapat diatur sebagai berikut.

1) (Baik) Soal sulit 25\%, soal sedang 50\%, soal mudah $25 \%$

2) (Sedang) Soal sulit $20 \%$, soal sedang $60 \%$, soal mudah $20 \%$

3) (Buruk) Soal sulit 15\%, soal sedang 70\%, soal mudah $15 \%$.
Dan dari hasil perhitungan profile matching penulis membuat klasifikasi daya pembeda soal sesuai dengan nilai yang dihasilkan dari tiap-tiap mahasiswa terhadap konsentrasi kejuruannya. Klasifikasi yang dibuat terdapat tiga kriteria yaitu baik, sedang dan buruk yang diambil dari hasil nilai minimum dan maksimum yang dihasilkan dari perhitungan profile matching. Berikut hasil klasifikasinya:

A: 4-5 = Baik

B: $2-3,9=$ sedang

C: $1-1,9=$ buruk

Total soal yang akan keluar bagi tiap-tiap mahasiswa terdapat 100 soal yang dibagi rata dengan berapa banyak variabel yang ada didalam konsentrasi tersebut . Soal yang akan dibuat terdapat 3 jenis soal dari tiap-tiap variabel mata kuliah yaitu mudah, sedang dan sulit. dari tiap-tiap variabel akan mendapatkan jumlah soal yang akan keluar sesuai dengan proporsi yang dihasilkan dari nilai tiap-tiap mahasiswa, Setiap variabel akan disediakan 100 soal mudah, 100 soal sedang, dan 100 soal sulit. Adapun daftar kategori soal yang telah di klasifikasi sesuai dengan data yang diambil dari hasil perhitungan profile matching. Berikut hasil klasifikasinya:

Tabel 3.5 Kategori Soal M KHOIRUL HAKIM AR Jurusan Teknik Informatika

\begin{tabular}{|c|c|c|c|c|c|c|c|c|c|c|c|}
\hline \multicolumn{12}{|c|}{ Kategori Soal Mobile Computing } \\
\hline \multicolumn{12}{|c|}{$\begin{array}{c}\text { M KHOIRUL HAKIM AR } \\
\text { NILAI }=4,2231 \text { (BAIK) } \\
\text { (Baik) Soal sulit 25\%, soal sedang 50\%, soal mudah 25\% }\end{array}$} \\
\hline \multicolumn{3}{|c|}{ H1 (25 SOAL) } & \multicolumn{3}{|c|}{ H2 (25 SOAL) } & \multicolumn{3}{|c|}{ H3 (25/2 SOAL) } & \multicolumn{3}{|c|}{ H4 (25 SOAL) } \\
\hline $\begin{array}{l}\text { mud } \\
\text { ah }\end{array}$ & $\begin{array}{c}\text { seda } \\
\text { ng }\end{array}$ & sul & $\begin{array}{c}\text { mud } \\
\text { ah }\end{array}$ & $\begin{array}{c}\text { seda } \\
\text { ng }\end{array}$ & $\begin{array}{c}\text { sul } \\
\text { it }\end{array}$ & $\begin{array}{l}\text { mud } \\
\text { ah }\end{array}$ & $\begin{array}{c}\text { seda } \\
\text { ng }\end{array}$ & sul & $\begin{array}{c}\text { mud } \\
\text { ah }\end{array}$ & $\begin{array}{c}\text { seda } \\
\text { ng }\end{array}$ & $\begin{array}{c}\text { sul } \\
\text { it }\end{array}$ \\
\hline 6 & 13 & 6 & 6 & 13 & 6 & 4 & 5 & 4 & 6 & 13 & 6 \\
\hline \multicolumn{12}{|c|}{$\begin{array}{c}\text { Kategori Soal Artificial Intelligence } \\
\text { NILAI }=3,1082 \text { (SEDANG) } \\
\text { (Sedang) Soal sulit } 20 \% \text {, soal sedang 60\%, soal mudah } 20 \%\end{array}$} \\
\hline \multicolumn{6}{|c|}{ H3 (25/2 SOAL) } & \multicolumn{6}{|c|}{ H5 (25 SOAL) } \\
\hline \multicolumn{2}{|c|}{ mudah } & \multicolumn{2}{|c|}{ sedang } & \multicolumn{2}{|c|}{ sulit } & \multicolumn{2}{|c|}{ mudah } & \multicolumn{2}{|c|}{ sedang } & \multicolumn{2}{|c|}{ sulit } \\
\hline \multicolumn{2}{|c|}{2} & \multicolumn{2}{|c|}{8} & \multicolumn{2}{|c|}{2} & \multicolumn{2}{|c|}{5} & \multicolumn{2}{|c|}{15} & \multicolumn{2}{|c|}{5} \\
\hline
\end{tabular}

Tabel 3.5 Kategori Soal SITI KHOIRIAH Jurusan Sistem Informasi

\begin{tabular}{|c|c|c|}
\hline \multicolumn{3}{|c|}{ Kategori Soal Application Development } \\
\hline \multicolumn{3}{|c|}{$\begin{array}{c}\text { SITI KHOIRIAH } \\
\text { NILAI = 4,6 (BAIK) } \\
\text { (Baik) Soal sulit 25\%, soal sedang 50\%, soal mudah 25\% } \\
\end{array}$} \\
\hline \multicolumn{3}{|c|}{ H1 (50 SOAL) } \\
\hline Mudah & sedang & sulit \\
\hline
\end{tabular}




\begin{tabular}{|c|c|c|}
\hline 13 & 25 & 12 \\
\hline \multicolumn{3}{|c|}{ Kategori Soal ERP } \\
NILAI = 4,6 (BAIK) \\
(Baik) Soal sulit 25\%, soal sedang 50\%, soal mudah 25\% \\
\hline \multicolumn{3}{|c|}{ H2 (50 SOAL) } \\
\hline mudah & sedang & sulit \\
\hline 13 & 25 & 12 \\
\hline
\end{tabular}

\subsection{Proses Pengacakan Soal dengan LCM}

a) Jurusan Teknik Informatika.

Tabel 3.6 Hasil pengacakan soal M KHOIRUL HAKIM AR.

\begin{tabular}{|c|c|c|c|}
\hline $\begin{array}{c}\text { HASIL } \\
\text { PERHITUNGAN } \\
\text { MANUAL }\end{array}$ & \multicolumn{3}{|c|}{ HASIL PERHITUNGAN EXEL } \\
\hline $\begin{array}{l}X(0)=0 \\
X(1)=(1(1)+6) \\
\bmod 101=7\end{array}$ & $\mathrm{n}$ & $\mathrm{a} X_{n}+c$ & $\mathbf{X}_{\mathrm{n}}$ \\
\hline $\begin{array}{l}X(2)=(1(7)+6) \\
\bmod 101=\mathbf{1 3}\end{array}$ & 1 & 7 & 7 \\
\hline$X(3)=(1(13)+6)$ & 2 & 13 & 13 \\
\hline $\begin{array}{l}\bmod 101=19 \\
X(4)=(1(19)+6)\end{array}$ & 3 & 19 & 19 \\
\hline & 4 & 25 & 25 \\
\hline $\begin{array}{l}\bmod 101=\mathbf{3 1} \\
X(6)=(1(31)+6)\end{array}$ & 5 & 31 & 31 \\
\hline $\bmod 101=\mathbf{3 7}$ & 6 & 37 & 37 \\
\hline
\end{tabular}

b) Jurusan Sistem Informasi.

Tabel 3.7 Hasil pengacakan soal SITI KHOIRIAH.

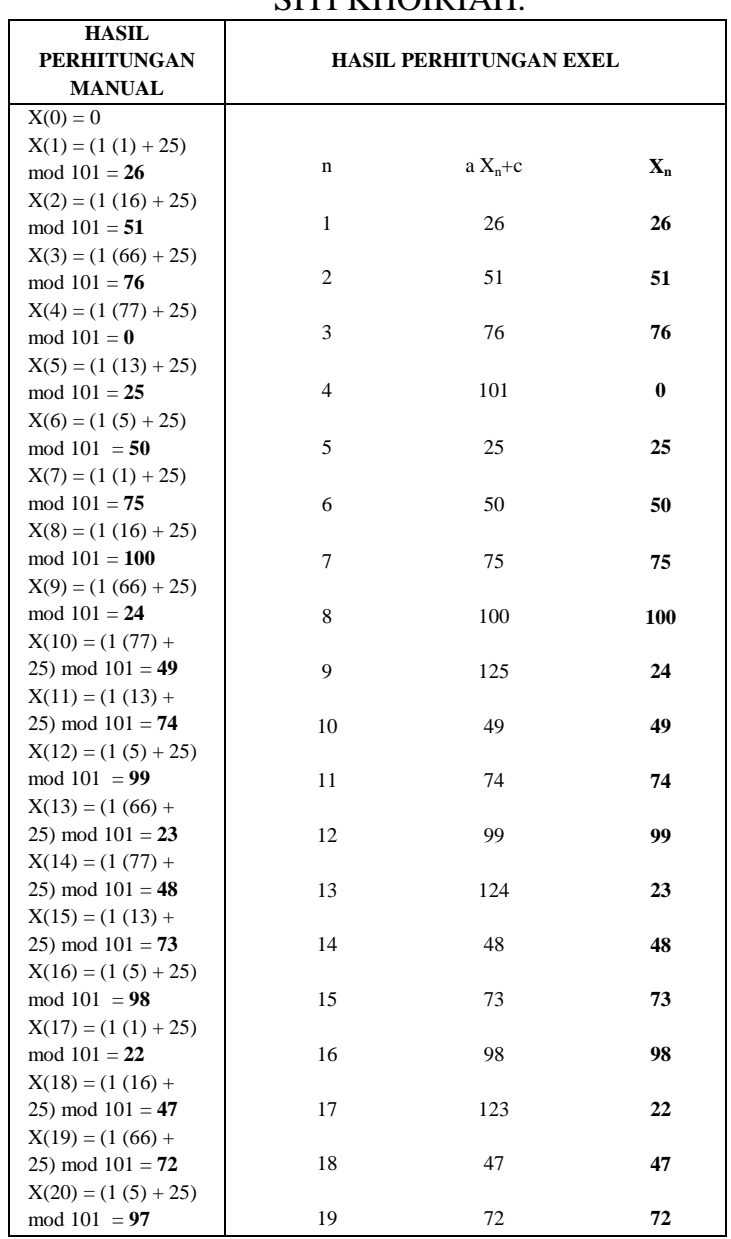

\begin{tabular}{|c|c|c|c|}
\hline $\begin{array}{l}\mathrm{X}(21)=(1(1)+25) \\
\bmod 101=\mathbf{2 1}\end{array}$ & 20 & 97 & 97 \\
\hline$X(22)=(1(16)+$ & & & \\
\hline 25) $\bmod 101=46$ & 21 & 122 & 21 \\
\hline$X(23)=(1(66)+$ & & & \\
\hline 25) $\bmod 101=71$ & 22 & 46 & 46 \\
\hline$X(24)=(1(16)+$ & & & \\
\hline 25) $\bmod 101=96$ & 23 & 71 & 71 \\
\hline $\begin{array}{l}X(25)=(1(66)+ \\
25) \bmod 101=\mathbf{2 0}\end{array}$ & 24 & 96 & 96 \\
\hline & 25 & 121 & 20 \\
\hline
\end{tabular}

\section{KESIMPULAN}

Berdasarkan hasil uraian dan pembahasan diatas, maka penulis dapat menyimpulkan beberapa hal sebagai berikut:

1. Metode profile matching yang digunakan sebagai pencocokan profile mahasiswa dapat menghasilkan nilai yang sesuai dengan profile tiap-tiap mahasiswa yang digunakan untuk menentukan kategori soal.

2. Metode linear congruent method (LCM) merupakan metode pengacakan soal yang masih terjadi munculnya angka yang sama tergantung dengan banyaknya soal yang diacak, semakin banyak soal maka semakin jarang pula terjadinya pengulangan.

3. Setiap mahasiswa mendapatkan soal yang berbeda-beda dan sesuai dengan kemampuan yang ada pada dirinya.

\section{DAFTAR PUSTAKA}

PERANCANGAN SISTEM APLIKASI UNDIAN BERHADIAH PADA PT. PS MAJU BERSAMA MENGGUNAKAN LINEAR CONGRUENT METHOD (LCM). (2014). Informasi dan Teknologi Ilmiah (INTI) Volume : IV, Nomor : 1, September $2014,73-81$

Dr. Kusrini, M. (2007). KONSEP DAN APLIKASI SISTEM PENDUKUNG KEPUTUSAN. (F. S. Suyantoro, Penyunt.) Yogyakarta: ANDI. 
Frieyadie. (2016). PENGGUNAAN METODE PROFILE MATCHING UNTUK SISTEM PENUNJANG KEPUTUSAN KENAIKAN JABATAN PADA INSTANSI PEMERINTAH. PARADIGMA Vol. XVIII. No.2 September 2016, 75-80.

Penyusun, D. T. (2017). BUKU PANDUAN PENULISAN SKRIPSI STMIK DHARMA WACANA. Metro: STMIK DHARMA WACANA.

Sutinah, E. (2017). Sistem Pendukung Keputusan Menggunakan Metode. INFORMATICS FOR EDUCATORS AND PROFESSIONALS, Vol. 2, No. 1, Desember 2017, 29-42, 29-42.

Tonni Limbong1, J. S. (2015). IMPLEMENTASI LINEAR CONGRUENT METHOD (LCM) UNTUK PENGACAKAN SOAL UJIAN BERKATEGORI. Proceedings Seminar Nasional Ilmu Komputer (SNIKOM) 2015, 11-14.

Sukmayasa, I. K. (n.d.). ANALISIS FAKTOR YANG MEMPENGARUHI KEPUTUSAN MAHASISWA DALAM PEMILIHAN MATA KULIAH KONSENTRASI JURUSAN PENDIDIKAN EKONOMI ANGKATAN 2012 DAN 2013.

Akhirina, TY. 2016. KOMPARASI METODE SIMPLE ADDITIVE WEIGHTING DAN PROFILE MATCHING PADA PEMILIHAN MITRA JASA PENGIRIMAN BARANG. JURNAL EDUKASI DAN PENELITIAN INFORMATIKA (JEPIN). Vol.

2, No. 1. Juni 2016: 27-33.

Arikunto, Suharsimi. (2006). DASAR-DASAR EVALUASI PENDIDIKAN. JAKARTA: BUMI AKSARA.

Arikunto, Suharsimi dan Jabar, Cepi Safruddin abdul. (2010). EVALUASI PROGRAM PENDIDIKAN: PEDOMAN TEORETIS PRAKTIS
BAGI MAHASISWA DAN PRAKTISI PENDIDIKAN EDISI KEDUA. Jakarta: Bumi Aksara.

Arifin, Zainal. (2009). EVALUASI PEMBELAJARAN PRINSIP, TEKNIK, PROSEDUR. Bandung: PT Remaja Rosdakarya.

PERANCANGAN SISTEM APLIKASI UNDIAN BERHADIAH PADA PT. PS MAJU BERSAMA MENGGUNAKAN LINEAR CONGRUENT METHOD (LCM). (2014). Informasi dan Teknologi Ilmiah (INTI) Volume : IV, Nomor : 1, September 2014, 73-81.

Sutinah, E. (2017). Sistem Pendukung Keputusan Menggunakan Metode. INFORMATICS FOR EDUCATORS AND PROFESSIONALS, Vol. 2, No. 1, Desember 2017, 29-42, 29-42.

Tonni Limbong1, J. S. (2015). IMPLEMENTASI LINEAR CONGRUENT METHOD (LCM) UNTUK PENGACAKAN SOAL UJIAN BERKATEGORI. Proceedings Seminar Nasional Ilmu Komputer (SNIKOM) 2015, 11-14.

Frieyadie. (2016). PENGGUNAAN METODE PROFILE MATCHING UNTUK SISTEM PENUNJANG KEPUTUSAN KENAIKAN JABATAN PADA INSTANSI PEMERINTAH. PARADIGMA Vol. XVIII. No.2 September 2016, 75-80.

Penyusun, D. T. (2017). BUKU PANDUAN PENULISAN SKRIPSI STMIK DHARMA WACANA. Metro: STMIK DHARMA WACANA. 